\title{
Resection of spinal hemangioblastoma
}

\author{
Giuseppe Lanzino, M.D., Saul F. Morales-Valero, M.D., and William E. Krauss, M.D. \\ Department of Neurologic Surgery, Mayo Clinic, Rochester, Minnesota
}

\begin{abstract}
Spinal cord hemangioblastomas occur as sporadic lesions or in the setting of Von Hippel-Lindau disease. In this intraoperative video we present a case of sporadic cervical cord hemangioblastoma and illustrate the main surgical steps to achieve safe and complete resection which include: identification and division of the feeding arteries; careful circumferential dissection of the tumor from the surrounding gliotic cord; identification, isolation and division of the main venous drainage and single piece removal of the tumor.

The video can be found here: http://youtu.be/I7DxqRrfTxc.

(http://thejns.org/doi/abs/10.3171/2014.V3.FOCUS14379)

KEY WORDS $\bullet$ hemangioblastoma $\bullet \quad$ spinal cord neoplasms
surgical procedure $\bullet \bullet \quad$ intraoperative video
\end{abstract}

Manuscript submitted July 1, 2014.

Accepted July 18, 2014.

Please include this information when citing this paper: DOI: 10.3171/2014.V3.FOCUS14379.

Address correspondence to: Giuseppe Lanzino, M.D., Department of Neurologic Surgery, Mayo Clinic, 200 SW First Street, Rochester, MN 55905. Email: lanzino.giuseppe@mayo.edu. 